\title{
Effects of topical treatment of second-degree burn wounds with Lactobacillus acidophilus on the wound healing process in male rats
}

\author{
Amir Abbas Barzegari ${ }^{*}$, Masood Hashemzaei ${ }^{1}$, Raheleh Majdani ${ }^{1}$, Ali-Reza Alihemmati ${ }^{2}$ \\ ${ }^{1}$ Department of biology, Faculty of Basic Science, University of Maragheh, Maragheh, East Azerbaijan Province, Iran \\ 2Department of Histology and Embryology, Tabriz University of Medical Sciences, Tabriz, Iran
}

\begin{tabular}{|c|c|}
\hline ART I C LE I NFO & BSTRACT \\
\hline *Corresponding author: & \multirow{10}{*}{$\begin{array}{l}\text { Despite preventive measures, incidence of burns is still one of the important medical problems. } \\
\text { Nowadays, it has been suggested that some strains of probiotic bacteria have beneficial effects in } \\
\text { treatment of skin injures like skin wounds. The aim of the present study was to evaluate the effects of } \\
\text { Lactobacillus acidophilus on second-degree burn wounds in rats. Second-degree burn wounds were } \\
\text { induced on the back of the } 60 \text { Wistar rats by contacting of a heated aluminum bar. After that, the rats } \\
\text { randomly assigned to negative control (received no treatment), vehicle control (received Eucerin, } \\
\text { daily) and experimental (received daily, an ointment of bacteria in Eucerin) groups. Macroscopic } \\
\text { assessment of wound healing was conducted by calculating the percent of wound healing in days } 3,7 \\
\text { and } 14 \text { post-burn. Moreover, wound samples were harvested for microscopic evaluation of wound } \\
\text { area. The results showed that in the experimental groups, the percent of wound healing, in the } 3^{\text {th }} \text { and } \\
7^{\text {th }} \text { days of experiments was significantly higher than control group. Moreover, in addition to } \\
\text { prevention of burn infection, the bacteria had beneficial effects on different aspects of wound healing } \\
\text { processes like reducing the inflammatory response and accelerating the granulation tissue formation } \\
\text { and re-epithelialization. Overall, the present study showed that the treatment of burn wounds with } L \text {. } \\
\text { acidophilus might accelerate the healing processes of second-degree burn wounds. }\end{array}$} \\
\hline nail.com & \\
\hline Article history: & \\
\hline ay 13 , & \\
\hline Acc & \\
\hline Keywords: & \\
\hline Lactobacillus acidop & \\
\hline & \\
\hline Burn & \\
\hline Rats & \\
\hline
\end{tabular}

Citation: Pharm Biomed Res 2017;3(3):23-30.

\section{Introduction}

Thermal injuries are always one of the risks that threats human health. Annually, many new cases of burns occur in the world, especially in low and middle-income countries (1-3), like the countries in Middle East region that may cause inability or even death of the injured ones (3). One of the most important functions of the skin, as the largest body organ, is its barrier function against the entry of pathogenic agents to the internal environment of the body. In burn, the skin loses its integrity, therefore, the main aim of current drugs that are used for the treatment of burns is to prevent of burn wound infection; because one of the most important reasons for death of the burn patients is the burn associated infections (4-5). Moreover, the use of such drugs usually associates with some unwanted side effects and microbial resistance to the drugs (6-9). In the second- and third-degree burns, the wound healing process is usually a long-term one. Therefore, finding new methods or treatments that, in addition to prevention of burn wound infection, could be able to accelerate the healing process of burn wounds and have fewer side effects are of great importance. Maybe, it is the reason why in spite of the current drugs and methods for the treatment of burn wounds, there are many new researches for finding more effective drugs or treatments for the wound management.

Bacterial therapy, the use of bacteria in treatment of diseases, has been considered as a potential tool for the treatment of some diseases (10-12). In the area, among the bacteria that have attracted much attention to themselves are probiotic bacteria. In definition, the probiotics are live microorganisms that if were ingested adequately by their hosts may have beneficial effects to their health (13). The safety of the probiotic bacteria have been proven to researchers, since the bacteria have been used in dairy products for many years with rare harmful effects on the users (14). The usefulness of probiotic bacteria in the treatment and prevention of some diseases have been shown in many researches (15-22). Among the diseases that have been treated with probiotic bacteria successfully are skin diseases (23-26). In this regard, new dermatological studies indicate that some strains of probiotic bacteria may have beneficial effects on the process of wound healing (27-31). To our knowledge, in spite of many studies that have evaluated the effects of oral administration of probiotics on skin problems, like wounds, there are few experiments about the topical use of probiotics for treatment of such conditions. 
Because, Lactobacillus acidophilus has antibacterial properties (32-34) and considering that the effects of probiotic bacteria are species or even strain dependent (35-37), the aim of the current study was to evaluate the effects of topical application of Lactobacillus acidophilus (ATCC 4356) on the process of seconddegree burn wound healing in male Wistar rats.

\section{Materials and Method}

\section{Animals}

In the present study, 60 healthy, intact male Wistar rats weighing 200-230 g were used. The experimental animals were purchased from Pasture Institute, Tehran, Iran. The animals randomly placed on 12 groups of 5 and housed in a standard animal room (Temperature 20-22 ${ }^{\circ} \mathrm{C}, 12-12$ dark-light cycle, $37 \%$ humidity). All the animals had free access to water and food pellets before and during the experimental procedures. To prevent of stress effects on the experiment results, before conducting the experiments, the animals were allowed to adapt to the new conditions for 10 days.

\section{Induction of second-degree burn wounds}

All the experimental protocols were conducted according to the eighth edition of the Guide for the Care and Use of Laboratory Animals (38) and approved by a local animal care and use committee (Number: 9631754). The method of induction of second-degree thermal injuries, in the animals, was according to the dos Santos Tavares Pereira's method et al., with little changes (39). In brief, first, the rats were anesthetized with the intraperitoneal injection of a mixture of xylazine $(10 \mathrm{mg} / \mathrm{kg}$ ) and ketamine $(90 \mathrm{mg} / \mathrm{kg})$ and the hair of backside of the animals, between the forelimbs, were removed with a clipper. Then the area was antisepticised with the $1 \%$ Povidone-iodine. In the next step, a solid aluminum bar (diameter $=1 \mathrm{~cm}$ ) with the temperature of nearly $97^{\circ} \mathrm{C}$ was placed on the area for 15 seconds. To prevent of animals suffering, after the induction of wounds, buprenorphine that has an almost long-lasting analgesic effects (40), was administered to all animals. Then each animal was placed in a separate cage for the next parts of the experiments. Figure 1 shows a typical burn wound induced by the methods on the dorsum of the rats.



Figure $1 \mathrm{~A}$ typical second-degree burn wound in the $1^{\text {st }}$ day after the wound induction with an aluminum bar, on the back of the rats.

\section{Preparation of topical ointment of L. acidophilus}

The probiotic bacteria, L. acidophilus, with ATCC 4356 were used in the experiments. The bacteria were cultured in the liquid MRS medium (QUELAB LABORATORIES INC, Canada) anaerobically with an anaerobic jar for $24 \mathrm{~h}$, at $37{ }^{\circ} \mathrm{C}$. Then the cultured medium centrifuged for $20 \mathrm{~min}$ in $12000 \mathrm{rpm}$. The precipitations were washed with phosphate buffer twice and then the fresh bacteria immediately were used for the treatment of wound area. For each experimental groups of rats, $10^{10}$ to $10^{11} \mathrm{CFU} / \mathrm{ml}$ of freshly cultured bacteria were mixed with $4 \mathrm{ml}$ of Eucerin and immediately used on the wound area (each rat received $0.8 \mathrm{ml}$ of the mixture).

\section{Experimental design}

After induction of the second-degree wounds (day 0), the rats randomly were assigned to four experimental, four vehicle control and four negative control groups of five. In the experimental groups, rats received an ointment that was a uniform mixture of bacteria with Eucerin in a daily schedule for 1, 3, 7 and 14 days after the wound induction. Rats in vehicle control groups received daily Eucerin ointment for the same days as the corresponding experimental groups and the rats in negative control groups, until the days of their euthanaization (days1, 3, 7, 14), received no treatments. For prevention of licking the woundtreated-area by other rats, after induction of burn wounds, all the animals kept in separate cages. Moreover, to avoid rubbing of the ointment on the wound to the cage walls, all the rats bandaged. Every day, the bandages replaced with a new one after daily treatment.

\section{Macroscopic evaluation of wound area}

The wound surface area in the days of $1,3,7$ and 14 after the induction of wounds were measured in each group until the euthanaization day. For the purpose, the wound area of each rat was covered, without any pressure, with a transparent nylon sheet and the periphery of wound area was drawn on the nylon. Then, with a digital camera that was placed in a fixed high above the drawings, the picture of the drawings was taken. At last, with Digimizer Software the wound surface area calculated using the picture of drawings in $\mathrm{mm}^{2}$. For the macroscopic evaluation of the wound healing process, the percent of wound healing or contraction, as the dynamic measure of wound healing were measured in all groups, in days 3, 7 and 14 postburn. The percent of contraction in wound surface area in day $\mathrm{x}$ was computed by the following formula:

$\mathrm{X}=\frac{A 1-A x}{A 1} \times 100$

In which $\mathrm{A} 1$ and $\mathrm{Ax}$ are the wound surface areas in the days 1 and $\mathrm{x}$. 


\section{Microscopic evaluation of wound area}

In the last day of the experiments (days 1, 3, 7, 14 for different groups), the wound surface areas were measured and then the animals in each group, after induction of a deep anesthesia, underwent trans-cardiac perfusion with normal saline and then neutral formalin (10\%). In the next step, the area of wounds with normal tissue surrounding them was harvested and fixed in the $10 \%$ formalin solution until the beginning of tissue processing time. After processing of the skin tissues, they embedded in paraffin and the resulting paraffin blocks were cut into sections of five $\mu \mathrm{m}$ thick. The sections were stained with hematoxylineosin method (41) and were evaluated for the inflammatory response, fibroblasts migration, granulation tissue formation and epithelialization. For this purpose, on each slide, five visual fields were analyzed by a blind histologist to the experimental conditions and the score of each evaluated parameter on the visual field determined on the basis of predetermined scoring methods (39). In the scoring method, the symbols of,,,-++++++ indicate absence, mild presence, moderate presence and strong presence, respectively. The histological analysis was performed in the examination of burn wound specimens, in the following ways: (1) inflammatory response, characterized by the presence of polymorphonuclear leukocytes (PNM), (2) granular tissue, characterized by the presence of fibroblasts, myofibroblasts, and neovascularization, (3) fibroblast migration, characterized by the density of fibroblast identified, (4) Epithelization, characterized by proliferation of squamous cells and keratinization.

\section{Bacterial wound culture}

For detection of possible presence of opportunistic bacteria on the wounds that had the signs of infections, the swabs of the wound area were cultured in general and selective media and for confirmation of the results of the bacterial cultures, complementary tests (catalase and oxidase tests) were conducted.

\section{Statistical analysis}

Quantitative data analysis was conducted using SPSS Software with factorial ANOVA method (Chicago, USA). In case of significant results observation, LSD post hoc was used for pairwise comparisons of different groups. The results were expressed as mean \pm SEM for quantitative data. $P<0.05$ was considered as significant.

\section{Results}

\section{Macroscopic results}

The results of calculating the percent of wound healing with respect to day 1 demonstrated that in the day 3 of experiments, the percent of wound healing in the experimental group (42.308\%) was significantly bigger than the negative control (28.868\%) and vehicle control (16.848\%) groups $(P<0.05$ and $P<0.01$ respectively). On the $7^{\text {th }}$ day post-burn, the percent of wound healing in experimental group (63.484 \%) was still higher than negative control (41.846\%) and vehicle control $(22.506 \%)$ groups $(P<0.01$ and $P<0.001$ respectively). However, on the day 14 post-burn, the percent of wound healing in the experimental group $(123.49 \%)$ was only significantly higher than the vehicle control $(107.096 \%)$ and $(P<0.05)$ but not the negative control (117.84\%) group (Figure 2).

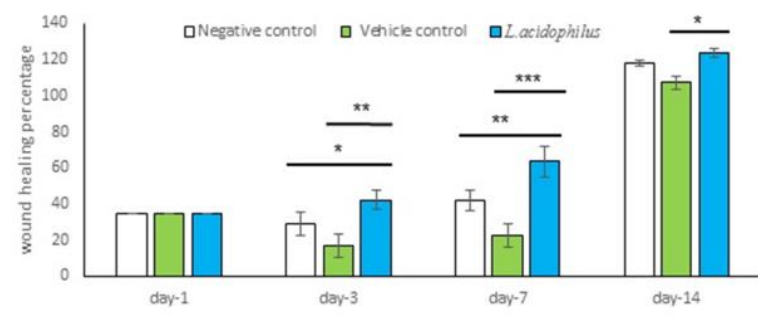

Figure 2 Except in the day 14 and with respect to negative control group, the wound healing percent in experimental groups, in all the days of the experiments was significantly higher than control groups in the same days. * indicates $P<0.05$, ** indicates $P<0.01$ and *** indicates $P<0.001$.

\section{Microscopic results}

\section{1-Inflammatory response}

Comparative evaluation of inflammatory response in tissue sections of the wound areas on different days showed that on the first day after the burn induction, the inflammatory response in all the negative control, vehicle control, and experimental groups was high. Moreover, whereas on the day 3 of experiments, the inflammatory response reduced in the experimental and negative control groups the response in the vehicle control group was still high. On the day 7 post-burn, the reduction in inflammatory response continued in the experimental group but the response was high in control ones, especially in the vehicle control group. On the day 14 of experiments, the lowest inflammatory response was observed in the experimental group compared with control the both control groups (Table 1).

\section{2-Fibroblastic migration}

In all groups, fibroblastic migration commenced on the day 3 and was the same in all the groups that belonged to a same trial day. The exception was the day 7 that the migration rate in the experimental group was higher than the both control groups (Table 1).

\section{3-Granulation tissue formation}

The formation of granulation tissue, in all groups, began on the day 3. On the day 7, the increase in the formation of granulation tissue was the highest in the 
Table 1 Histopathological analysis on the degree of the inflammatory intensity, presence of granulation tissue, fibroblast migration and re-epithelialization in the skin of wound area, in $1^{\text {st }}, 3^{\text {th }}, 7^{\text {th }}$ and $14^{\text {th }}$ days after the burn induction. The symbols of,,,-++++++ demonstrate the absence, mild presence, moderate presence and strong presence, respectively.

\begin{tabular}{|c|c|c|c|c|c|}
\hline Groups & $\begin{array}{l}\text { Time } \\
\text { (Day) }\end{array}$ & $\begin{array}{c}\text { Inflammatory } \\
\text { response }\end{array}$ & $\begin{array}{c}\text { Fibroblast } \\
\text { migration }\end{array}$ & $\begin{array}{c}\text { Granulation } \\
\text { tissue }\end{array}$ & Epithelialization \\
\hline \multirow{4}{*}{ Control- } & $1^{\text {st }}$ & +++ & - & - & - \\
\hline & $3^{\text {th }}$ & ++ & + & + & + \\
\hline & $7^{\text {th }}$ & ++ & ++ & ++ & + \\
\hline & $14^{\text {th }}$ & ++ & ++ & +++ & ++ \\
\hline \multirow{4}{*}{ Control + } & $1^{\text {st }}$ & +++ & - & - & - \\
\hline & $3^{\text {th }}$ & +++ & + & + & + \\
\hline & $7^{\text {th }}$ & +++ & ++ & ++ & + \\
\hline & $14^{\text {th }}$ & ++ & ++ & ++ & ++ \\
\hline \multirow{4}{*}{$\begin{array}{c}L . \\
\text { acidophilus }\end{array}$} & $1^{\mathrm{st}}$ & +++ & - & - & - \\
\hline & $3^{\text {th }}$ & ++ & + & + & ++ \\
\hline & $7^{\text {th }}$ & + & +++ & +++ & ++ \\
\hline & $14^{\text {th }}$ & + & ++ & ++ & +++ \\
\hline
\end{tabular}

experimental group compared with control groups while on the day 14 the negative control group has the highest density of the tissue (Table 1).

\section{4-Epithelialization}

In all groups, epithelialization first observed on the day 3 ; however, the rate of epithelialization on the $3^{\text {rd }}, 7^{\text {th }}$ and $14^{\text {th }}$ days of the experiment, was higher in the experimental groups than the both control groups (Table 1).

Moreover, figures 3-6 show the tissue changes in the days $1,3,7$ and 14 post-burn in the experimental groups.

\section{Wound-culturing results}

The wound swabs of the Eucerin treated wounds that had the infection signs were cultured first in tryptone soy agar (TSA) medium, for $24 \mathrm{~h}$ in $37{ }^{\circ} \mathrm{C}$. Tow distinguished colonies of bacteria were observed in the medium. Then, gram staining showed that in a mix culture we had both gram-positive coccus and gramnegative bacillus. For purification of the culture and acquiring single colonies, fresh cultures of this plate prepared using the TSA medium and gram staining was conducted to confirm the presence of single colonies of gram-positive and gram-negative bacteria. Then, catalase and oxidase tests were conducted using the fresh cultures. The results of the tests showed that the bacteria on the both media were catalase positive. The oxidase test in MacConkey agar culture was positive, too. This was another reason that might indicate for the presence of gram-negative bacteria, pseudomonas aeruginosa on the wound area. In the last stage, the samples of fresh culture of TSA medium added to the Mannitol salt agar (MSA) medium and incubated for 24 $\mathrm{h}$ in $37^{\circ} \mathrm{C}$. The color of the medium changed into yellow indicating the presence of gram-positive bacteria, Staphylococcus aureus in the primary mix culture. Overall, the results showed that the wounds of the Eucerin treated groups were probably contaminated with the opportunistic bacteria, P. aeruginosa and S. aureus (Figure 7).

\section{Discussion}

In the current study, macroscopic and microscopic evaluation of wounds area showed that the wounds that were treated with L. acidophilus had higher present of healing than the control ones, especially on the days 3 and 7 post-burn. Moreover, the results showed that the application of Eucerin ointment on the wounds by itself might hinder the wound healing process. Eucerin, as the base for making of topical drugs, has moistening properties. It seems that the results of the study are contrary to the current idea that moist wound healing is faster than the same process in the dry wounds (42). It is true that wounds healing is faster in the moist wounds but another aspect of moistening the wound is that the moisture on the wound may provide a more convenient microenvironment for opportunistic bacteria that infect the wounds. In the study, we did not do any efforts for prevention of the wound infection, because one of the aim of the current study was to evaluate the potential of the probiotic bacteria for inhibition of growth and colonization of opportunistic bacteria that may infect the wound surface. The likelihood of finding opportunistic bacteria like Staphylococcus aureus, in colonies of laboratory rodents and transmission of the bacteria from laboratory staffs to the animals is relatively high (43). Moreover, some animal facilities may be contaminated with Pseudomonas aeruginosa especially through tap water(44 - 45). Therefore, the 


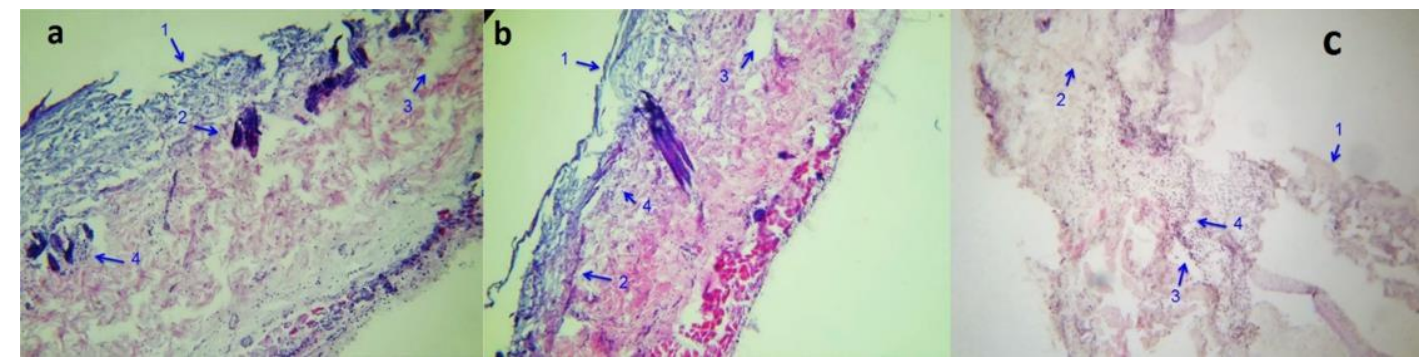

Figure 3 Necrosis of superficial tissues (1), denaturation of deep collagen fibers (2), widespread edema (3) and leucocyte infiltration (4) in the day 1. Letters a, b and c show the wound tissue sections of negative control, vehicle control and the experimental groups, respectively.

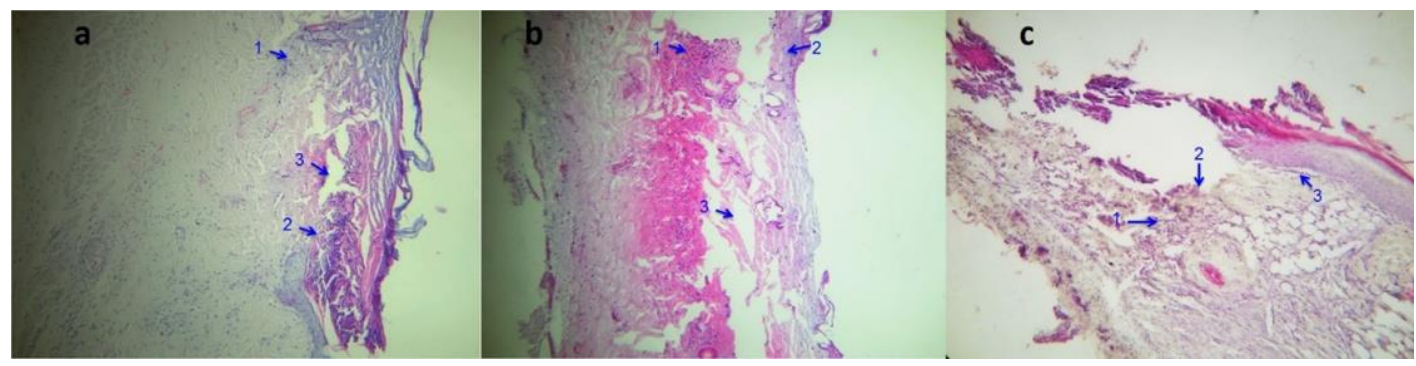

Figure 4 Leucocyte infiltration (1), necrotic tissue formation (2), disruption of dermal tissue in the day 3 of the experiments. Letters $\mathrm{a}, \mathrm{b}$ and $\mathrm{c}$ show the wound tissue sections of negative control, vehicle control and the experimental groups, respectively.

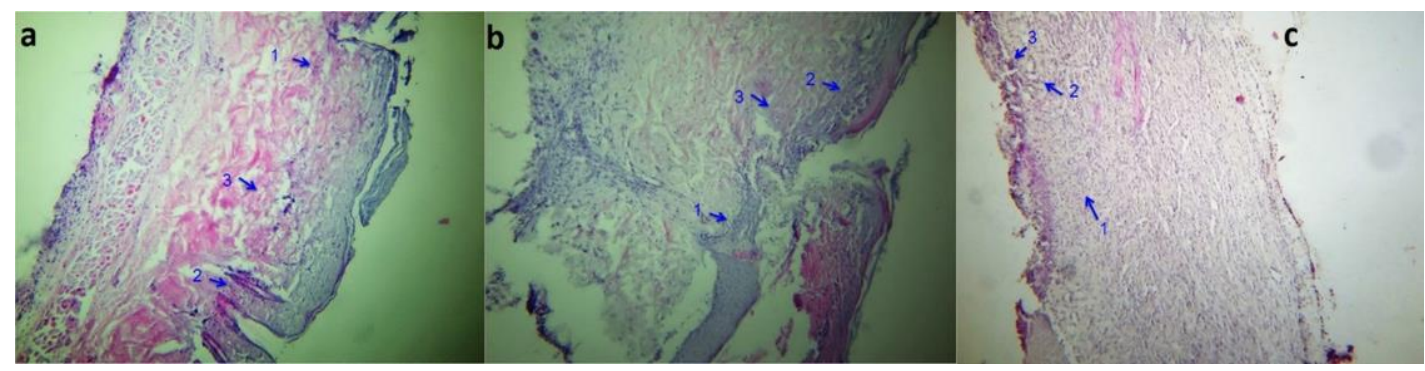

Figure 5 Fibroblast proliferation and accumulation of collagen tissue (1) neovascularization (2) and infiltration of inflammatory cells (3) in the day 7 of the experiments. Letters a, b and c show the wound tissue sections of negative control, vehicle control and the experimental groups, respectively.

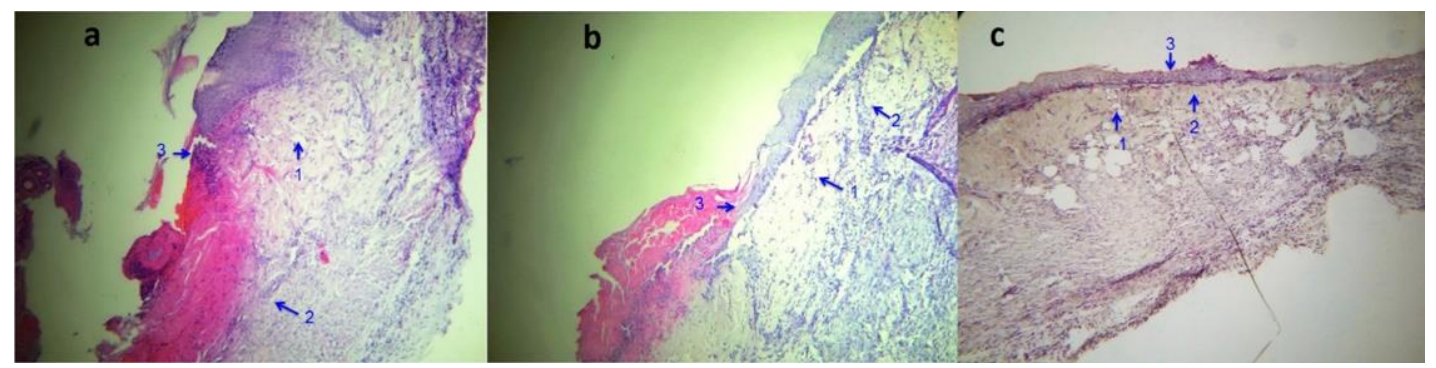

Figure 6 Increase in the density of vessels (1), the reduction of inflammatory and edema responses (2) and the more regular pattern of the epithelium (3) in the day14 post-burn. Letters a, b and c show the wound tissue sections of negative control, vehicle control and the experimental groups, respectively. 


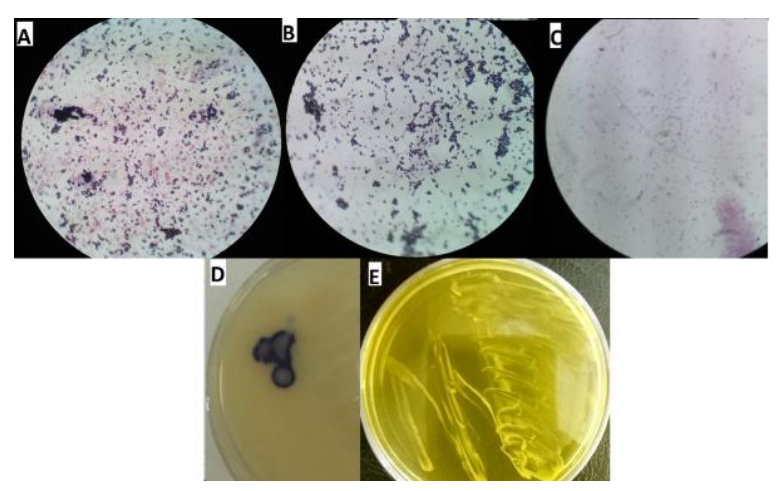

Figure 7 Part (A) shows the gram staining of the bacteria in the first swab culture using the TSA medium. It demonstrates a mix culture of both gram-positive cocci and gram-negative bacilli in the medium. Parts (B) and (c) represent the gram staining of pure cultures of gram-positive cocci and gram-negative bacilli after passaging the first culture for acquiring the single colonies in TSA medium, respectively. Part (D) demonstrates the positive result of oxidase test on MacConkey agar medium, indicating the presence of gram-negative bacteria, pseudomonas aeruginosa. Part (E) shows the yellow colonies in Mannitol salt agar medium, indicating the presence of Staphylococcus aureus.

wound surface of the rats in our animal room might be prone to the infection by these opportunistic bacteria. The results of culturing the wounds surface swabs confirmed the presence of opportunistic bacteria $(S$. aureus and $P$. aeroginosa) on the wound surface in the Eucerin treated groups that had the signs of infection. The appearance of the burn wound area on the rats that received only the Eucerin ointment had the characteristics criteria for the diagnosis of local infection, like yellow to green color and delayed healing, too. However, the wounds of untreated rats or the animals that received the mixture of Eucerin with the L. acidophilus (the experimental group) had the normal appearance (figure 8). Also, previous studies have shown that covering the wounds with gauzes don't act as physical barrier to prevent of bacteria to enter the wound area (46). Therefore, in our experiments the chance of pathogenic bacterial entrance to the wound area was nearly the same in all groups. The presence of pathogenic bacteria on the wound area, by elevating the pro-inflammatory cytokines like IL-1 and TNF- $\alpha$ may intensify the inflammatory response in the wound area (47). Thus, the wound infection postpones the overall wounds healing process. The infection signs in the rats of the vehicle control groups were evident, and the rats in these groups had the highest inflammatory response compared to the other groups; therefore, the vehicle control group had the least percentage of wound healing even in comparison with negative control groups. The role of probiotic bacteria in prevention of local infections has been shown in some previous studies. In Hansen and Jespersen patent invention, the probiotic lactic acid bacteria could interfere with the growth and colonization of pathogenic bacteria on the wound surface with different mechanisms (48). Moreover, in another experiment, topical application of Lactobacillus reuteri by preventing of colonization of opportunistic bacteria could prevent of wound infection (49). In addition, previous research has shown that $L$. acidophilus by itself has antibacterial effects against some pathogenic bacteria including the opportunistic bacteria (Staphylococcus aureus and Pseudomonas aeruginosa) that may infect the burn wounds $(32-34,50)$. Thus, in rats of the experimental groups, the probiotic bacteria might be successful in competition with pathogenic bacteria that may infect wounds and thus excluded the pathogenic bacteria for growth and colonization in the moist wound area of the experimental groups; therefore, we did not see the signs of the infected wounds in this group. Therefore, the results may be indicative of antibacterial properties of L. acidophilus in our experiments.

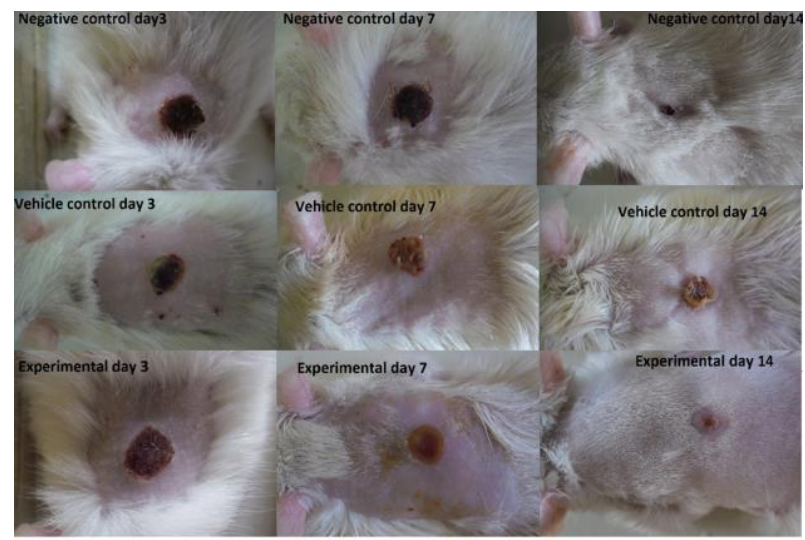

Figure 8 In the Eucerin treated groups, infection signs like yellow to green color on the wound area appeared in the day 3 post-burn and increased until the last day of the experiment but the negative control and vehicle control groups had normal appearances. Moreover, the delay in the wound healing in the Eucerin-treated group is another sign that may indicates the wound infection.

In the next part of the experiments, different stages involve in the wound healing including inflammatory and proliferative phases were evaluated. The results showed that the inflammatory response in the experimental groups was lower than the control ones. The inflammatory phase provides natural defense against the infections and termination of the phase is necessary for the entrance to the next phase, i.e. the proliferative phase. Therefore, the more inflammatory 
phase terminated sooner, the less time is necessary for the entrance to the next stage and thus the overall time for wound healing will be shorter. As we saw in table 1, in the bacterial treated group the inflammatory phase terminated sooner than the Eucerin or untreated groups. This finding is in accordance with the results of previous experiments indicating that some strains of probiotic bacteria have anti-inflammatory effects (37, 51-52). Moreover, it is clear that if less infection presents on the wound, then the wound inflammatory phase will shorten. Therefore, the probiotic bacteria may have some anti-inflammatory and anti-infection effects. On the other hand, the results of the current experiments showed that on the day 7 of the experiments, the migration of the fibroblasts and the formation of the granulation tissue as parts of the second phase of the wound healing (i.e. proliferative phase) was greater in the experimental groups compared to the control ones. In addition, in experimental group, the rate of epithelialization in the days of 3, 7 and 14 after the burn induction was higher than control ones. Thus, in the bacterial treated wounds, all aspects of proliferative phase of the wound healing, including the fibroblastic migration, formation of granulation tissue and re-epithelialization was greater than the control groups. Studies indicate that the contraction of the wounds or reduction in the wound surface area take places in this stage. The macroscopic results of the experiments support the microscopic results, as comparison of the present of wound healing between the experimental and control groups showed that in the experimental group the most healing percent occurred in the $7^{\text {th }}$ days of the trials. Moreover, our results about the improvement of epithelialization in probiotic treated wounds are in good agreement with the Mohammed Saeed et.al findings in which in a Keratinocyte Scratch Assays the Lactobacillus rhamnosus GG lysate could increase the re-epithelialization by Promoting keratinocyte Migration (53). In general, our microscopic results showed that the treatment of the burn wound area with the probiotic $L$. acidophilus bacteria might reduce the period of inflammatory phase and improved the different aspects of proliferative phases of the wound healing.

Our experimental results are in agreement with the findings of some previous researches that indicate the positive role of topical application of probiotic bacteria in the wound healing process. For example, Peral et al, in a limited clinical experiment on patients with second and third-degree burn wounds, showed that local treatment of the patients' wounds with Lactobacillus plantarum may reduce the bacterial load of the wounds and increase the rate of wound healing processes (54). In another experiments, it was shown that the topical use of kefir grains on the thermal burn wounds, accelerate the wound healing even as compared to the silver sulfadiazine treated groups (55). Moreover, there are patent inventions that claim the use of lactic acid probiotic bacteria may speed up the wound healing process and reduce the microbial infection of wounds by different mechanisms (48).

Conclusion: The net result of our experiments is that topical application of L. acidophilus (ATCC 4356), on the burn wounds, may be useful in accelerating the burn wound healing processes.

Although the results of the current study are in favor of the use of the L. acidophilus (ATCC 4356) for the treatment of thermal burn wounds, before it can be approved for such applications in human, more preclinical and clinical investigations are needed. The reason is that there are some structural and physiological differences between the skins and wound healing processes in the two species.

\section{Acknowledgments}

The current study was conducted using the facilities of the animal house of the University of Maragheh and we thank the dean of the Faculty of Basic Science, Dr. Mohammad Mehdizadeh for his supports.

\section{Conflict of interests}

There is no conflict of interests to declare.

\section{References}

1. Organization WH. A WHO plan for burn prevention and care. 2008.

2. Ahuja RB, Bhattacharya S. Burns in the developing world and burn disasters. BMJ 2004;329:447-9.

3. Rybarczyk MM, Schafer JM, Elm CM, Sarvepalli S, Vaswani PA, Balhara KS, et al. A systematic review of burn injuries in low-and middle-income countries: epidemiology in the WHO-defined African Region. Afr J Emerg Med 2017;7:30-7.

4. Williams FN, Herndon DN, Hawkins HK, Lee JO, Cox RA, Kulp GA, et al. The leading causes of death after burn injury in a single pediatric burn center. Crit care 2009;13:R183.

5. Donati L, Scamazzo F, Gervasoni M, Magliano A, Stankov B, Fraschini F. Infection and antibiotic therapy in 4000 burned patients treated in Milan, Italy, between 1976 and 1988. Burns 1993;19:345-8.

6. Cho A-R. Effect of silver sulfadiazine on the skin cell proliferation and wound healing process in hairless mouse 2nd degree burn model. J Pharm Investig 2002;32:113-7.

7. Percival S, Bowler P, Russell D. Bacterial resistance to silver in wound care. J Hosp Infect 2005;60:1-7.

8. Chatterjee M, Anju C, Biswas L, Kumar VA, Mohan CG, Biswas R Antibiotic resistance in Pseudomonas aeruginosa and alternative therapeutic options. Int J Med Microbiol 2016;306:48-58.

9. Kong EF, Johnson JK, Jabra-Rizk MA. Community-associated methicillin-resistant Staphylococcus aureus: an Enemy amidst Us. PLoS Pathog 2016;12:e1005837.

10. Guarino A, Canani RB, Spagnuolo MI, Albano F, Di Benedetto L Oral bacterial therapy reduces the duration of symptoms and of viral excretion in children with mild diarrhea. J Pediatr Gastroenterol Nutr 1997;25:516-9.

11. Lee MC, Lin LH, Hung KL, Wu HY. Oral bacterial therapy promotes recovery from acute diarrhea in children. Acta Paediatr Taiwan 2001;42:301-5.

12. Felgner S, Kocijancic D, Frahm M, Weiss S. Bacteria in cancer therapy: renaissance of an old concept. Int J Microbiol 
2016;2016.

13. Araya M, Morelli L, Reid G, Sanders M, Stanton C, Pineiro M. Joint FAO/WHO Working Group report on drafting guidelines for the evaluation of probiotics in food. London, Canada: World Health Organization, Food and Agriculture Organization of the United Nations 2002.

14. Saxelin M, Rautelin H, Salminen S, Mäkelä P. Safety of commercial products with viable lactobacillus strains. Infect Dis Clin Pract 1996;5:331-5.

15. Nguyen T, Kang J, Lee M. Characterization of Lactobacillus plantarum PH04, a potential probiotic bacterium with cholesterol-lowering effects. Int J Food Microbiol 2007;113:35861.

16. Isolauri E, Kirjavainen P, Salminen S. Probiotics: a role in the treatment of intestinal infection and inflammation?. Gut 2002;50:54-9.

17. Madsen K, Cornish A, Soper P, McKaigney C, Jijon H, Yachimec C, et al. Probiotic bacteria enhance murine and human intestinal epithelial barrier function. Gastroenterology 2001;121:580-91.

18. Moayyedi P, Ford AC, Talley NJ, Cremonini F, Foxx-orenstein A, Brandt L, et al. The efficacy of probiotics in the therapy of irritable bowel syndrome: a systematic review. Gut 2010;59:325-32.

19. McFarland LV. Meta-analysis of probiotics for the prevention of antibiotic associated diarrhea and the treatment of Clostridium difficile disease. Am J Gastroenterol 2006;101:812-22.

20. Lam EK, Yu L, Wong HP, Wu WK, Shin VY, Tai EK, et al. Probiotic Lactobacillus rhamnosus GG enhances gastric ulcer healing in rats. Eur J Pharmacol 2007;565:171-9.

21. Schreck Bird A, Gregory PJ, Jalloh MA, Risoldi Cochrane Z, Hein DJ. Probiotics for the treatment of infantile colic: a systematic review. J Pharm Pract 2017;30:366-74.

22. Wallace CJ, Milev R. The effects of probiotics on depressive symptoms in humans: a systematic review. Ann Gen Psychiatry 2017;16:14.

23. Drago L, Iemoli E, Rodighiero V, Nicola L, De Vecchi E, Piconi S. Effects of Lactobacillus salivarius LS01 (DSM 22775) treatment on adult atopic dermatitis: a randomized placebo-controlled study. Int J Immunopathol Pharmacol 2011;24:1037-48.

24. Yeşilova Y, Çalka Ö, Akdeniz N, Berktaş M. Effect of probiotics on the treatment of children with atopic dermatitis. Ann Dermatol 2012;24:189-93.

25. Weston S, Halbert A, Richmond P, Prescott SL. Effects of probiotics on atopic dermatitis: a randomised controlled trial. Arch Dis Child 2005;90:892-7.

26. Notay M, Foolad N, Vaughn AR, Sivamani RK. Probiotics, Prebiotics, and Synbiotics for the Treatment and Prevention of Adult Dermatological Diseases. Am J Clin Dermatol 2017;18:721-32.

27. Rodrigues KL, Caputo LRG, Carvalho JCT, Evangelista J, Schneedorf JM. Antimicrobial and healing activity of kefir and kefiran extract. Int J Antimicrob Agents 2005;25:404-8.

28. El-Ghazely M, Mahmoud W, Atia M, Eldip E. Effect of probiotic administration in the therapy of pediatric thermal burn. Ann Burns Fire Disasters 2016;29:268-72.

29. Mohseni S, Bayani M, Bahmani F, Tajabadi-Ebrahimi M, Bayani MA, Jafari $P$, et al. The beneficial effects of probiotic administration on wound healing and metabolic status in patients with diabetic foot ulcer: A randomized, double-blind, placebo-controlled trial. Diabetes Metab Res Rev 2017.

30. Argenta A, Satish L, Gallo P, Liu F, Kathju S. Local application of probiotic bacteria prophylaxes against sepsis and death resulting from burn wound infection. PLoS One 2016;11:e0165294.

31. Shahsafi M. The Effects of Bacillus subtilis Probiotic on Cutaneous Wound Healing in Rats. NBM 2017;5:43-7.

32. Karska-Wysocki B, Bazo M, Smoragiewicz W. Antibacterial activity of Lactobacillus acidophilus and Lactobacillus casei against methicillin-resistant Staphylococcus aureus (MRSA). Microbiol Res 2010;165:674-86.

33. MM A, Hassan Z, HM N, YA E. Evaluation on antibacterial activity of lactobacillus acidophilus strains isolated from honey. 2012;9:807-17.

34. Walencka E, Różalska S, Sadowska B, Różalska B. The influence of Lactobacillus acidophilus-derived surfactants on staphylococcal adhesion and biofilm formation. Folia Microbiol 2008;53:61-6.

35. Özdemir Ö. Various effects of different probiotic strains in allergic disorders: an update from laboratory and clinical data. Clin Exp Immunol 2010;160:295-304.

36. Maassen CB, Claassen E. Strain-dependent effects of probiotic lactobacilli on EAE autoimmunity. Vaccine 2008;26:2056-7.

37. Kekkonen RA, Lummela N, Karjalainen H, Latvala S, Tynkkynen $S$, Järvenpää $S$, et al. Probiotic intervention has strain-specific anti-inflammatory effects in healthy adults. World J Gastroenterol 2008;14:2029-36.

38. council NR. Guide for the care and use of laboratory animals. National Academies Press;(2010).

39. Pereira T, Dos Santos D, Lima-Ribeiro MHM, de Pontes-Filho NT, Carneiro-Leão AMdA, Correia MTdS. Development of animal model for studying deep second-degree thermal burns. Biomed Res Int 2012;2012.

40. Gades NM, Danneman PJ, Wixson SK, Tolley EA. The magnitude and duration of the analgesic effect of morphine, butorphanol, and buprenorphine in rats and mice. J Am Assoc Lab Anim Sci 2000;39:8-13.

41. Fischer AH, Jacobson KA, Rose J, Zeller R. Hematoxylin and eosin staining of tissue and cell sections. CSH Protoc 2008; 2008.

42. Field CK, Kerstein MD. Overview of wound healing in a moist environment. Am J Surg 1994;167:S2-S6.

43. Hayashimoto N, Morita H, Ishida T, Yasuda M, Kameda S, Uchida $\mathrm{R}$, et al. Current microbiological status of laboratory mice and rats in experimental facilities in Japan. Exp Anim 2013;62:41-8.

44. Urano T, Noguchi K, Jiang G, TSUKUMI K. Survey of Pseudomonas aeruginosa contamination in human beings and laboratory animals. Exp Anim 1995;44:233-9.

45. Baker DG. Natural pathogens of laboratory mice, rats, and rabbits and their effects on research. Clin Microbiol Rev 1998;11:231-66.

46. Lawrence JC. Dressings and wound infection. Am J Surg 1994;167:21-4.

47. Eming SA, Krieg T, Davidson JM. Inflammation in wound repair: molecular and cellular mechanisms. J Investig Dermatol 2007;127:514-25.

48. Hansen JE, Jespersen LK. Wound or tissue dressing comprising lactic acid bacteria. US Patent 0143447 A1, 10 June 2010

49. Prince T, McBain AJ, O'Neill CA. Lactobacillus reuteri protects epidermal keratinocytes from Staphylococcus aureus-induced cell death by competitive exclusion. Appl Environ Microbiol 2012;78:5119-26.

50. Jebur MS. Therapeutic efficacy of Lactobacillus acidophilus against bacterial isolates from burn wounds. N Am J Med Sci 2010;2:586-91.

51. Della Riccia D, Bizzini F, Perilli M, Polimeni A, Trinchieri V, Amicosante G, et al. Anti-inflammatory effects of Lactobacillus brevis (CD2) on periodontal disease. Oral Dis 2007;13:376-85.

52. von Schillde MA, Hörmannsperger G, Weiher M, Alpert CA, Hahne $\mathrm{H}$, Bäuerl $\mathrm{C}$, et al. Lactocepin secreted by Lactobacillus exerts anti-inflammatory effects by selectively degrading proinflammatory chemokines. Cell Host Microbe 2012;11:38796.

53. Mohammedsaeed W, Cruickshank S, McBain AJ, O'Neill CA. Lactobacillus rhamnosus GG lysate increases re-epithelialization of keratinocyte scratch assays by promoting migration. Sci Rep 2015;5:16147.

54. Peral MC, Huaman Martinez MA, Valdez JC. Bacteriotherapy with Lactobacillus plantarum in burns. Int Wound J 2009;6:7381.

55. Huseini HF, Rahimzadeh G, Fazeli MR, Mehrazma M, Salehi M. Evaluation of wound healing activities of kefir products. Burns 2012;38:719-23. 